
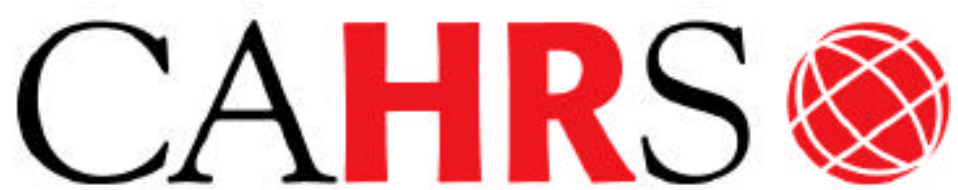

Center for Advanced Human Resource Studies
CAHRS / Cornell University 187 Ives Hall

Ithaca, NY 14853-3901 USA

Tel. 607 255-9358

www.ilr.cornell.edu/CAHRS/

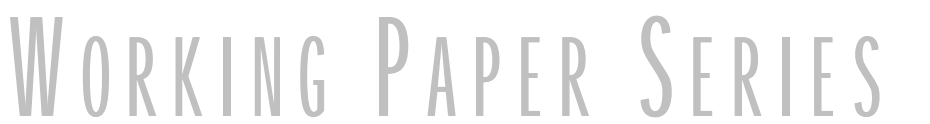

\title{
Voluntary Turnover and Job Performance: Curvilinearity and the Moderating Influences of Salary Growth and Promotions
}

Charlie 0. Trevor

Barry Gerhart

John W. Boudreau

Working Paper 9 7- 03 
Voluntary Turnover and Job Performance:

Curvilinearity and the Moderating Influences

of Salary Growth and Promotions

\author{
Charlie O. Trevor \\ Cornell University \\ School of Industrial and Labor Relations \\ Ithaca, New York 14853 \\ Barry Gerhart \\ Cornell University \\ School of Industrial and Labor Relations \\ Ithaca, New York 14853 \\ John W. Boudreau \\ Cornell University \\ School of Industrial and Labor Relations \\ Ithaca, New York 14853
}

Working Paper \# 97-03

http://www.ilr.cornell.edu/CAHRS

This paper has not undergone formal review or approval of the faculty of the ILR School. It is intended to make results of research, conferences, and projects available to others interested in human resource management in preliminary form to encourage discussion and suggestions. 


\title{
Voluntary Turnover and Job Performance: \\ Curvilinearity and the Moderating Influences \\ of Salary Growth and Promotions
}

\section{Charlie O. Trevor, Barry Gerhart, and John W. Boudreau \\ Cornell University}

\begin{abstract}
The relationship between job performance and voluntary employee turnover was investigated for 5,143 exempt employees in a single firm. As hypothesized, support was found for E. F Jackofsky's (1984) curvilinear hypothesis, as turnover was higher for low and high performers than it was for average performers. Two potential moderators of the curvilinearity were examined in an attempt to explain conflicting results in the performance-turnover literature. As predicted, low salary growth and high promotions each produced a more pronounced curvilinear performance-turnover relationship. Most notably, salary growth effects on turnover were greatest for high performers, with high salary growth predicting rather low turnover for these employees, whereas low salary growth predicted extremely high turnover. Additionally, once salary growth was controlled, promotions positively predicted turnover; with poor performer turnover most strongly affected.
\end{abstract}

The cost of voluntary employee turnover depends on many factors, including the relative supply and cost of replacements in either the internal or external labor market, the amount of training invested in the employee, and the performance level of the employee (Boudreau \& Berger, 1985; Dalton, Todor, \& Krackhardt, 1982; Hollenbeck \& Williams, 1986). Where replacement costs are low and average performance of replacements is expected to be high, organizations can benefit from turnover of poor performers. In contrast, turnover of high performers is more likely to be dysfunctional for the organization (e.g., Hollenbeck \& Williams, 1986; Park, Ofori-Dankworth, \& Bishop, 1994; Schwab, 1991). Thus, it is important to identify the conditions under which employees of different performance levels are most likely to voluntarily leave the organization.

This is especially true at the organization's higher job levels, where, for several reasons, high performer turnover is more costly than at lower job levels. For instance, because the standard deviation of performance tends to be greater in more complex jobs (Boudreau, 1992), top performer turnover in higher level jobs results in greater performance losses than similar turnover in lower level jobs. Moreover, performance at higher job levels tends to have a larger effect on firm success and is more difficult and expensive to replace. Finally, turnover of top performers in higher level jobs may result in the loss of future leaders of the organization, suggesting that the importance of top performer turnover in the salaried ranks extends well

Charlie O. Trevor, Barry Gerhart, and John W. Boudreau, Department of Human Resource Studies, School of Industrial and Labor Relations, Cornell University. Barry Gerhart is now at the Owen Graduate School of Management, Vanderbilt University. We thank Ellen Jackofsky for thoughtful comments.

Correspondence concerning this article should be addressed to Charlie O. Trevor, School of Industrial and Labor Relations, Cornell University, 393 Ives Hall, Ithaca, New York. Electronic mail may be sent via Internet to cot1@cornell.edu 
beyond the short-term performance losses and transaction costs associated with such withdrawal.

What is known about the performance-turnover relationship? Clearly, turnover decreases as performance increases. McEvoy and Cascio (1987), Bycio, Hackett, and Alvares (1990), and Williams and Livingstone (1994) have reported weighted uncorrected correlations of -.24, -.17, and -.16, respectively, in meta-analyses of voluntary performance and turnover. However, these and other authors have emphasized that such linear associations may not fully capture the nature of the relationship and that research should also address the potentially more informative issues of nonlinearity and moderating effects (e.g., Jackofsky, 1984; McEvoy \& Cascio,1987; Schwab, 1991; Williams \& Livingstone, 1994). With this study, we have attempted to contribute to the evidence that exists on both issues and, for the first time, bring the curvilinear and moderator elements together into one framework.

\section{Review of the Literature}

The March and Simon (1958) turnover model, from which several other turnover models have been derived, suggests that voluntary employee separation is a function of perceived ease of movement and perceived desirability of movement. However, theoretical models of voluntary turnover often yield no simple prediction concerning the link with employee performance (McEvoy \& Cascio, 1987). One important reason may be the integral effects of contextual factors on the performance-turnover relationship (Schwab, 1991). For instance, the perceived desirability of movement and subsequent turnover at various performance levels likely depend upon the nature of an organization's financial rewards (e.g., Dreher, 1982; Gerhart \& Milkovich, 1992; Jackofsky, 1984; Porter \& Lawler, 1968; Schwab, 1991; Steers \& Mowday, 1981). Moreover, it is the combined effects of perceived ease of movement and perceived desirability of movement that must be considered, yielding further complexity in prediction. As an illustration of how the reward context and the dual determinants of turnover can contribute to prediction uncertainty, in cases where the pay-performance relationship is strong, high performers may be subject to the countervailing forces of high perceived ease of movement and low perceived movement desirability. In short, simply characterizing the performance-turnover relationship as a negative linear association captures neither the relationship's complexity nor the importance of its context (e.g., McEvoy \& Cascio, 1987; Schwab, 1991; Williams \& Livingstone, 1994).

\section{Curvilinearity}

Finding a linear effect of performance on turnover does not preclude nonlinearity, although most studies fail to test for it. As a step toward a more encompassing model of performance and turnover, Jackofsky (1984) suggested that there will often be a curvilinear 
relationship, such that turnover is most probable among both low performers and high performers. Jackofsky characterized adequate performers as being allowed by the firm to remain and low ease of movement. She argued that low performers may be "pushed out" because of "actual or perceived threat of administrative action" (p. 79). Steers and Mowday (1981) also viewed low performers as likely turnover candidates due to low satisfaction with the job's intrinsic rewards. These effects should combine to leave poor performers with high movement desirability and a high turnover rate, despite the low ease of movement. Finally, Jackofsky maintained that high performers would enjoy numerous employment alternatives and, via this higher ease of movement, would separate more frequently. Thus, high performers, by virtue of high movement ease and the absence of the actual or perceived threats facing poor performers, would seem to possess greater discretion in the choice to separate.

Limited empirical support exists for Jackofsky's (1984) curvilinear hypothesis, finding that low and high performers were more likely to leave than average performers (e.g., Jackofsky, Ferris, \& Breckenridge, 1986; Mossholder, Bedeian, Norris, Giles, \& Feild, 1988; Williams, 1990). Complicating the issue of curvilinearity, however, are recent studies that explicitly tested for but failed to find this relationship. Birnbaum and Somers (1993) reported no evidence of either a curvilinear or linear relationship between performance and voluntary turnover in a sample of 142 nurses. A second study (Wright \& Bonett, 1993) that failed to find a curvilinear relationship concluded that the job performance of 93 human services supervisors was positively linearly associated with voluntary turnover.

A recent meta-analysis provides perhaps the strongest support for expecting a curvilinear relationship between performance and turnover. As one aspect of a large scale meta-analytic study of job performance and voluntary turnover, Williams and Livingstone (1994) examined eight quadratic semipartial correlations from four different studies that investigated curvilinearity. These authors concluded that there is evidence across these studies of a curvilinear performance-turnover relationship. However; we suggest that the curvilinearity issue remains open because the meta-analysis was based on only eight data points from four studies and included neither the Wright and Bonett (1993) nor the Birnbaum and Somers (1993) unsupportive research. Moreover, Williams and Livingstone acknowledged the need for more studies to increase the accuracy and stability of the meta-analytic test. Further, they noted that interpretation of the exact shape of and reasons for curvilinearity is best made on a study by-study basis.

Based on the theoretical framework proposed by Jackofsky (1984) and the empirical research to date, we hypothesized: 
There will be a curvilinear relationship between job performance and voluntary turnover. Specifically, turnover will be highest among low and high performers, and lower among average performers. (Hypothesis 1)

\section{Salary Growth as a Moderator}

Although we find the curvilinear model to be appealing, it does seem that further contextual considerations are necessary. For high performers, Jackofsky's (1984) model seems to assume that high ease of movement is unlikely to be severely undermined by March and Simon's (1958) perceived desirability of movement. This assumption seems reasonable to the extent that pay growth and performance are not closely linked. That is, high performer turnover should tend to be high under the condition of low reward contingency because movement desirability should increase as reward inequity increases (e.g., Gerhart \& Milkovich, 1992), thereby joining high movement ease in precipitating turnover. Thus, the literature's numerous indications of the prevalence of a weak pay-performance link (e.g., Garelik, 1984; Hay Group, 1994; Lawler, 1981, 1989; Milkovich \& Newman, 1993; Teel, 1986; see Heneman, 1990 for a review) would help to explain research supporting the curvilinear hypothesis. Because high performers are of such critical importance to the firm (e.g., Boudreau \& Berger, 1985), a crucial issue to be investigated here is whether this assumption -- that for high performers, high ease of movement is not undermined by movement desirability -- holds up when pay growth and performance are closely linked, which should result in lower movement desirability.

Although most performance-turnover research to date has not explicitly considered the text, the applicable research does suggest that the reward system may be an important moderator of the performance-turnover relationship. For example, Zenger (1992) reported that turnover intentions were greatest among moderately high and extremely low performers in two firms with strong ties between pay and extreme performance. Similarly, Johns (1989) found that better performers reported more turnover cognitions when rewards were not perceived as contingent upon performance (this relationship held for self-report performance and for ratings of promotion potential, but not for supervisor ratings of performance). Park, Ofori-Dankworth, and Bishop (1994) reported that only poor performer turnover was associated (positively) with the presence of individual incentives. However, these studies were unable to analyze actual individual turnover, with both Zenger and Johns using attitudes regarding turnover and Park et al. surveying small firm personnel directors to determine the estimated portion of voluntary leavers who were of various performance levels. Although Williams (1990) did measure actual turnover, he did not find strong support for reward contingency as a moderator of performance effects. Additionally, the failure of the Wright and Bonett (1993) study of human services 
supervisors to find a hypothesized curvilinear performance-turnover relationship may have been driven by the presence of, according to the authors, little or no link between pay and performance although it was not a variable in the study. It is likely that poor performers were paid well relative to their performance, subsequently experienced low desirability of movement (perhaps augmented by the public sector's frequently greater insulation from pressure to leave voluntarily), and separated rather infrequently, essentially flattening the hypothesized curve.

Finally, the Williams and Livingstone (1994) meta-analysis tested reward contingency as a moderator of the linear performance-turnover relationship. Because the studies incorporated into the meta-analysis did not tend to be concerned with rewards, coding for the moderator was done by virtue of any mention of reward contingency in the study. Despite the high interrater reliability, given merit pay's notorious failure in significantly distinguishing between performance levels in the distribution of pay increases (e.g., Lawler, 1989), and the looseness with which pay for performance can be referred to in studies, such coding might seem to raise validity concerns. However, because several of the studies were of sales representatives (where reward contingencies tend to be less ambiguous and more likely), and because Williams and Livingstone contacted the authors of studies that were unclear on the issue, the finding of a stronger negative performance-turnover relationship when reward contingencies were present lends substantial support to contingent pay as a moderator of the linear performance-turnover relationship.

However, Schwab (1991) suggested that meta-analysis may lead to faulty conclusions when looking at complex moderator relationships, such as those likely to comprise the performance-turnover relationship. Thus, individual studies are needed to carve out more specifics regarding rewards as a moderator than the general meta-analytic finding could provide (Williams \& Livingstone, 1994). In this study, we attempt to extend Jackofsky's (1984) curvilinear model to predict performance level specific turnover under different pay arrangements. In doing so, we make use of a model (Gerhart, 1990a) that incorporates a pay-performance link by specifying salary growth (i.e., average annual pay increase) to be largely a function of post-hire factors, such as average performance rating. Specifically, our study is unique in that a large sample and measures of actual pay growth and turnover allow us to explicitly examine pay growth relative to performance as a moderator of an underlying curvilinear performance turnover relationship. As a main effect, we assume that increased salary growth should decrease turnover through diminished desirability of movement. However, this negative effect should be stronger as performance, and movement ease and discretion, increases. That is, in the presence of performance based rewards, the otherwise high mover of high performers 
should resemble the low movement tendencies of average performers as the high ease of movement is offset by diminished desirability of movement. In contrast, for poor performers, increasing salary growth should also lessen desirability of movement, but should have less of an effect on turnover due to actual or perceived pressures to leave (Jackofsky 1984 ) and low intrinsic rewards (Steers \& Mowday, 1981).

The negative effect of salary growth on turnover will be greatest at high performance levels, such that the curvilinear performance-turnover relationship will be more propounced when salary growth is low.

(Hypothesis 2)

\section{Promotions as a Main Effect and Moderator}

The second moderator of interest in this study is promotions. Promotions can be a major determinant in overall salary growth over time (Gerhart \& Milkovich, 1989). With a promotion the employee typically receives a pay increase and moves to a lower relative position in a new pay grade, thereby having the opportunity to earn larger and perhaps more frequent within-grade increases (Milkovich \& Newman, 1993). Hence, it is expected that highly promoted employees to experience greater salary growth and be less likely to voluntarily leave the organization. High performers who have been passed over for promotions and find themselves at the top of the salary range with little opportunity for salary growth may perceive pay inequity and entertain the possibility of leaving (i.e., an increase in perceived desirability of movement). Indeed, in studies that used actual promotions (as opposed to promotion satisfaction or opportunities) and actual turnover, Stumpf and Dawley (1981) and Dreher (1982) predicted and found significant negative associations between promotions and employee turnover.

In contrast, there is also reason to believe that receiving promotions might increase employee movement. In explaining a positive relationship between performance and turnover for tenured faculty, Schwab (1991) maintained that indicators of performance that are visible to the external market may play a large role in the ability to acquire a different job. Specifically, signals that can be communicated to potential employers as evidence of individual employee worth (e.g., research citations) may increase actual ease of movement. Within the firm, promotions are used as such signals of ability (Forbes \& Wertheim, 1995; Rosenbaum, 1984; Sheridan, Slocum, Buda, \& Thompson, 1990). It is reasonable to expect that promotions, which can be listed on one's resume along with the accompanying new job titles, also qualify as one of Schwab's externally visible indicators and, hence, could positively influence turnover.

Further conceptual support for a positive promotion turnover relationship exists in the labor economics literature. Authors from this field have claimed that promotions reduce the informational gap between the current and alternative employers (Ricarti Costa, 1988), enhance 
labor market visibility (Milgrom \& Oster, 1987), and signal worker productivity to other potential employers (Waldman, 1990). Lazear (1986) argued that competing employers, when better informed about worker quality in other firms, are more likely to hire those employees away. Accordingly, Bernhardt and Scoones (1993) developed model of strategic promotion and wage decisions based in part on the assumption that promotions induce turnover by communicating employee value to competing firms.

The positive promotions-turnover relationship suggested by these visibility and signaling arguments may be reconcilable with the negative associations between promotions and turnover found by Stumpf and Dawley (1981) and Dreher (1982). Neither study controlled for pay growth, which can be closely tied to promotions (Gerhart \& Milkovich, 1989). Because we hypothesized that pay growth is also related (negatively) to turnover, we suggest that it is likely that the reported negative associations between promotions and turnover may in fact have been driven by pay growth's relationship with both variables. Therefore, it appears that the net effect of promotions alone (i.e., controlling for pay growth) has not been studied empirically in organizational research. Although we recognize that pay growth and promotions can be highly correlated, we suggest that their conceptual distinction and predicted opposing influences on turnover warrant examining independent effects.

Promotions may diminish movement desirability because of the immediate salary growth, its potential growth in the future, and perhaps such factors as increased recognition, challenge, and job satisfaction. On the other hand, promotions also provide the employee with relatively objective and verifiable evidence of ability that can be used in the external job market. We suggest that the majority of promotions' potential negative effect on turnover is tied to salary growth, and once this is controlled for, the positive effect of promotions on ease of movement will outweigh its other negative effects on movement desirability. Because promotions, to our knowledge, has never been empirically tested with pay growth controlled and a hypothesized positive effect on turnover, we included a main effect hypothesis. Of course, we acknowledge that this hypothesis is subordinate to our interest in promotions as a moderator.

Controlling for salary growth promotions will be positively related to turnover (Hypothesis 3a)

The potential for promotions to moderate the performance-turnover relationship has not been addressed in turnover studies. However, the signaling rationale for the main effect in Hypothesis 3a, coupled with research on hiring decisions under uncertainty and an application of the social cognition literature, seems to suggest that the effect of promotions on turnover may vary by performance level. Lower performers are sometimes able to garner promotions because 
promotions, particularly at early stages of the career (as in our sample), can be a function of factors that are not directly performance based, such as assessment center performance (Thornton \& Byham, 1982); education (Forbes \& Wertheim, 1995), type of training program (Sheridan et al., 1990), functional area (Veiga, 1985), breadth of experience (Fortes \& Piercy, 1991), and power and politics (Ferris, Buckley, \& Allen, 1992; Sheridan et al., 1990).

Additionally, features of the internal labor market, such as hierarchical levels and demographics (e.g., seniority or a small cohort at a certain level), can reduce the association between promotion and performance. Although lower performers receive promotions, we suggest that the decision context for considering hiring these employees involves fewer performance indicators than the high performer case and, consequently, greater uncertainty. This varying degree of uncertainty lends itself to a potentially differential weighting of promotions in the external market.

The selection process is concerned with making assessments largely based on limited imperfect information on job candidates (Nieva \& Gutek, 1980). The result may be a greater reliance on heuristics, such as stereotyping when making hiring decisions than when making decisions about current employees about whom more relevant information is known (Gerhart, 1990a). Indeed, research reviews (Dipboye, 1985; Olian, Schwab, \& Haberfeld, 1988) suggest that discrimination against women is more likely in selection than in performance appraisal. Furthermore, Tosi and Einbender's (1985) meta-analysis indicates that female applicants are more likely to be subject to discrimination as job relevant information decreases. Together, this research seems to suggest that a salient piece of information (i.e., gender) is more heavily weighted under greater degrees of uncertainty. Similarly, Kelley (1972) maintained that, when information is scarce, a discounting principle can guide causal inference. This principle holds that when making an inference (e.g., whether a job applicant is worth hiring), any one piece of information (e.g., a promotion) is less heavily weighted to the extent that other potentially relevant pieces of information are available (e.g., better references, greater job knowledge).

Clearly, high performers are more likely to possess numerous indicators that can be used to signal worth to the market. For example, consider two employees. The low performer has a resume with a promotion and the accompanying change in job title. The high performer possesses a more impressive resume (i.e., one that also includes other ability indicators, such as professional certification), a history of successful projects that can be discussed with a potential employer, greater job knowledge to relate, and several references happy to enthusiastically make a recommendation. Because there is less relevant information (i.e., greater uncertainty) when considering the low performer, the potential employer may weight the promotion heavier than in the case for the high performer, for whom any single performance 
indicator may be discounted to the extent that others are available. In other words, the low performer has all of his/her employability in one basket, whereas the high performer, with a bigger basket overall, has a more diversified profile, such that any one element is not as large of an influence on employability.

Hence, through application of Kelley's (1972) discounting principle to the uncertain hiring context, we suggest that promotions may have a greater effect on an outside employer's inference regarding ability and effort (and on the subsequent job offer and turnover) for the low performer, who has little complementary information, than for the high performer, who has more.

The positive effect of promotions on turnover (controlling for salary growth) will be greatest at lower performance levels, such that the curvilinear performance-turnover relationship will be more pronounced when promotions are high. (Hypothesis $3 b$ )

In summary, research suggests that the performance turnover relationship is negative when constrained to a linear association but may in fact be curvilinear. Additionally, authors of recent turnover studies have recognized that contextual factors may moderate the effect of performance on turnover. Studying these issues is particularly important at salaried levels, where dysfunctional (i.e., high performer) turnover involves greater short-term costs than similar turnover at lower levels and may also result in the loss of future leaders of the organization. Consequently, in this investigation we attempted to test whether the performance-turnover relationship for exempt employees is curvilinear and whether salary growth and promotions moderate that curvilinearity.

\section{Method}

\section{Sample}

The sample was composed of all exempt employees $(N=5,143)$ hired in a single organization between 1983 and 1988 who were either (a) still employed as of January 1, 1990 ( $n=3,635)$, (b) had voluntarily resigned prior to that date $(n=1,188)$, or (c) had separated involuntarily $(n=320)$. Because our sample included all exempt hires in a large organization, a broad spectrum of job types is represented. Included employees were distributed across a number of different divisions and locations, but in each case, the product or service was tied to the petroleum industry.

\section{Measures}

Voluntary turnover. This variable was coded 1 if the employee had resigned voluntarily as of January 1, 1990. 1t was coded as 0 if the employee was still employed with the organization as of that date. Involuntary terminations were also coded as 0 , allowing our 
statistical model to make use of the fact that these employees did not voluntarily separate during their tenure (see Analyses section). Failure to include involuntary terminations may result in bias and significant loss of information (Morita, Lee, \& Mowday, 1993).

Average performance rating. This variable represents the average of all supervisor performance ratings received subsequent to the hire date. Supervisors used a single item, five point, global rating scale in yearly assessments of employee performance. The performance scale ranged from $1=$ lowest to 5 = highest, with the five categories representing levels of consistency in meeting and exceeding the basic requirements of the job. The mean interyear correlation of performance ratings was .45 . Incorporating this correlation and the employee average of 3.05 performance ratings into the Spearman-Brown prophecy formula yielded an estimate of reliability for performance ratings of .71 . However, the .45 mean interyear correlation likely incorporates error attributable to change in performance as well as random error (e.g., by including the Year 1 with Year 5 correlation of performance ratings in the calculation of the mean interyear correlation, the average likely suffers from performance changes over that time period). Therefore, as our mean interyear performance correlation, it is arguably more accurate to use the average consecutive year correlation of performance ratings (.53) or the King, Hunter; and Schmidt (1980) .60 reliability standard for supervisor ratings. By incorporating these into Spearman-Brown, the calculation yielded reliabilities of .77 and .82 , respectively.

In terms of the validity of the performance ratings, the distribution of scores provides some support for the organization's contention that performance appraisal was taken very seriously. Discriminating between employees and avoiding leniency bias were emphasized in the performance appraisal training conducted by the organization's human resources department. With a mean of $2.74(S D=.66)$ on the 5-point scale and with only $6.1 \%$ of employees averaging a performance rating of 4.0 or more, it is clear that few employees were actually considered top performers. Additionally, meta-analytic evidence suggests that supervisor ratings are predictive of job performance across situations and are no less valid than objective measures such as production quantity (Nathan \& Alexander, 1988).

Although the averaging of performance ratings resulted in an interval measure of performance, we primarily used average performance level categories in an attempt to examine turnover effects more closely at specific performance levels. First, we created these levels by rounding average performance to each half point of the 5-point scale. This resulted in nine categories, with 3 as the omitted comparison performance level in analyses that used performance as a categorical predictor and consequently incorporated eight dummy variables. 
Salary growth. Average annual salary growth adjusted for inflation into 1989 dollars was defined as the change from the starting salary to the last observed salary divided by the time interval between the two salaries. As such, it reflects salary growth stemming from both withinand between-grade (promotion) increases. The mean amount of time between the first and last salary observations was 3.09 years. The mean annual average salary increase was $9.8 \%(6.1 \%$ when adjusted for cost-of-living changes).

Promotions. The promotions variable was constructed by dividing the employee's total number of promotions by years of tenure. This operationalization presumes that in terms of signaling the external market, the raw number of promotions would not be as informative as a time indexed measure. For example, two promotions in 6 years would be less appealing to a prospective new employer than would two promotions in 3 years.

Control variables. Several factors that could reasonably be expected to be related to turnover and the predictors of interest were controlled for in the study. Except when models were stratified by hire year (see Analyses section), dummy variables were included for year of hire to adjust for the nature of the labor market and unmeasured industry factors present in the year each cohort was hired. In these equations, 1983 was the comparison year. Salary level was included in the models and defined as the final pay level on each employee's record; thus, this variable denotes salary at time of turnover for those who left the firm and 1989 salary for those who stayed. In 1989 dollars, the mean starting salary was $\$ 31,824$, and the last observed salary was $\$ 38,184$. Additionally, we controlled for marital status and age.

Analyses

Data on tenure with the organization were treated as survival time (also known as failure time) data (Kalbfleisch \& Prentice, 1980). To estimate the influence of the independent variables on the survival probabilities, we used a proportional hazards rate model (Cox, 1972). For statistical software we used the PHREG procedure (SAS Institute. 1991). The proportional hazards model has previously been applied in organizational research in studies of employee turnover (Judge \& Watanabe, 1995; Morita, Lee, \& Mowday, 1989; Morita et al., 1993; Sheridan, 1992) and employee absenteeism (Fichman, 1989; Harrison \& Hulin, 1989). This model is partially parametric in that it does not impose any distributional assumptions on the data. However, it does assume that hazard functions (i.e., the probability of turnover and conditional on tenure) at different levels of an independent variable are proportional to some unknown baseline hazard function.

One advantage of proportional hazards modeling is its use of information on survival time (i.e., tenure), rather than relying solely on a simple dichotomous turnover dependent 
variable. This provides a vehicle for partially accounting for censored data, such as that resulting from the tenure of employees who are involuntarily terminated. That is, because the dependent variable is voluntary turnover conditional on tenure, the model incorporates information on the tenure of involuntary terminations coupled with the fact that there was no voluntary turnover during that tenure. Additionally, employees who resign 1 day into the study are differentiated from those that quit 2 years into the data collection window. Such information can be lost when treating turnover simply as a dichotomous outcome, which may result in conflicting findings from the two approaches, the potential for which was empirically demonstrated by Morita et al (1993).

We stratified our proportional hazards analyses by hire year, which allows each hire year cohort to be in proportion to potentially different baseline hazard functions. This decision was made after examining the graphs of natural logarithms of the cumulative baseline hazard functions for each hire year cohort as a check of the proportionality assumption (Andersen, 1982). Although the functions appeared to be proportional to each other, with each new hire year 1 year of potential tenure is lost because 1989 is the final year of data for all hire year cohorts. Thus, we could not be sure that each year's baseline function would remain proportional over the entire tenure domain, and we took the more conservative stratification approach. Hence, our proportional hazards regression model, prior to adding interactions, was

$$
\begin{aligned}
h_{i}(t ; x) & =h_{i}(t) \exp \left[\beta_{\mathrm{j}}\left(X_{\text {controls }}\right)+\beta_{2}\left(X_{\text {performance }}\right)\right. \\
& \left.+\beta_{3}\left(X_{\text {salary growth }}\right)+\beta_{4}\left(X_{\text {promos }}\right)\right]
\end{aligned}
$$

where $h_{i}(t ; x)=$ the hazard function (i.e., conditional probability of turnover) at time $t$, for employees hired in year $i$ with predictors $x, h(t)=$ the baseline hazard function for individuals hired in year $i, \beta=$ the estimated regression weights, and $X=$ the explanatory variables.

Table 1

\begin{tabular}{|c|c|c|c|c|c|c|c|c|c|c|c|c|}
\hline & Variable & $M$ & SD & 1 & 2 & 3 & 4 & 5 & 6 & 7 & 8 & 9 \\
\hline & Turnover & 0.23 & 0.42 & - & & & & & & & & \\
\hline 2. & Tenure & 3.18 & 1.60 & -.24 & - & & & & & & & \\
\hline 3. & Performance & 2.74 & 0.66 & -.20 & .19 & - & & & & & & \\
\hline & Salary growth & 2.00 & 1.66 & -.28 & .09 & .30 & - & & & & & \\
\hline 5. & Promotions & 0.41 & 0.43 & -.12 & .00 & .06 & .66 & - & & & & \\
\hline & Salary & 38.18 & 15.55 & -.20 & .16 & .28 & .38 & -.07 & - & & & \\
\hline 7. & Age & 33.16 & 7.42 & -.07 & .19 & .06 & -.25 & -.34 & .21 & - & & \\
\hline & Marital status & 0.54 & 0.50 & -.06 & .14 & .11 & -.11 & -.19 & .19 & .31 & - & \\
\hline & Hire year & $1,985.71$ & 1.65 & -.20 & -.71 & .03 & .13 & .10 & .03 & -.21 & -.11 & - \\
\hline
\end{tabular}

Means, Standard Deviations, and Correlations $(N=5,143)$

Note. Correlations greater than \pm .05 are significant at $p<.001$ (two-tailed). 
Whereas this main effects model is conceptually correct, we note that in most models performance is treated as a nine level categorical variable and $\beta_{2}$ is thus a vector of eight regression weights. These coefficients estimate the effects of each of the $g$ - 1 (i.e., 8 performance dummy variables compared with the effect of the omitted performance level (category 3.0). Interaction effects were estimated through creating $g$ - 1 cross product terms by multiplying each dummy variable by the moderator in question. For comparison purposes, we also conducted parallel analyses with performance and performance squared as an interval rather than categorical measure.

\section{Results}

Means, standard deviations, and correlations for the study's variables are presented in Table 1. As expected, the zero-order linear relationship between performance and turnover was negative, replicating the results of three recent meta-analyses (Bycio, Hackett, \& Alvares, 1990; McEvoy \& Cascio, 1987; Williams \& Livingstone, 1994). Also of interest in these correlational results, promotions were negatively related to turnover, seemingly in opposition to Hypotheses $3 a$ and $3 b$. However, as discussed below, partialing out the effects of salary growth reveals an entirely different conclusion regarding promotions and turnover.

Proportional Hazards Analyses

To test Hypothesis 1, that the relationship between voluntary turnover and performance is curvilinear; we first applied the multiple regression procedure advocated by Cohen and Cohen (1983) to the proportional hazards regression case. This was done by testing a model with the continuous performance variable, rather than the categorical performance variable, and then adding its squared term. Cortina (1993) demonstrated the difficulty of partialing quadratic and interaction effects from each other when the two terms in an interaction term were highly correlated (i.e., $x_{1}$ multiplied by $x_{2}$ approaches $x_{1}^{1}$ and $x^{2}{ }_{2}$ ). Although the rationale for the argument was that researchers should include squared terms when examining an interaction, Cortina also suggested that theoretically important interactions should be included when examining quadratic terms. Thus, because performance and salary growth are components of an interaction term that we are interested in and are moderately correlated $(r=.30)$, we also included a performance by salary growth cross product term in the equations. ${ }^{1}$ As evidence of curvilinearity, the squared term coefficient and the increase in model fit were significant (see Table 2).

\footnotetext{
${ }^{1}$ Similarly, because $x_{1}$ times $x_{2}$ can approach $x^{3}{ }_{1}$ and $x_{2}{ }_{2}$ if $x_{1}$ and $x_{2}$ are highly correlated, we needed to include cubed terms in the moderated curvilinear analysis that used continuous performance and a Salary Growth X Squared Continuous Performance
} 
We then examined the validity of this study's categorical performance approach to modeling curvilinearity in the performance-turnover relationship. This approach allowed us to examine the shape of the relationship in a more detailed fashion and did not confine the shape to a parabolic nature. Substituting the eight performance dummies (with performance category 3.0 as the omitted comparison level) for the continuous performance measure and its square provided eight performance coefficients, five of which were significant. We found this model to be a significantly better fit to the data than the nested model without performance. We computed $D$ statistics for the proportional hazards models, which are similar to the $R^{2}$ values in more common regression models in that (though applying to qualitatively different dependent variables) both represent variance explained (Hintze, 1989). ${ }^{2}$ Hence, we were able to use $D$ to compare the categorical performance model with the quadratic continuous performance model. Table 2 reveals that the categorical performance model accounts for slightly more conditional turnover variance than does the quadratic model. This difference would have been even greater without the salary growth by performance interaction term that adds to total variance explained in the quadratic model. Moreover, the large positive coefficients for performance categories 1.0 and 5.0 suggest curvilinearity, as turnover probability is substantially greater for the lowest and highest performers than for average performers (i.e., employees in the omitted performance category). Thus, the results of the categorical and continuous performance approaches support performance-turnover curvilinearity and the use of a categorical performance measure in its assessment.

interaction. In doing so, we partialed out any of the interaction effects that might actually have been a result of a cubic relationship between either term and turnover (J.M. Cortina, personal communication, March, 1996).

${ }^{2}$ As Sheridan (1992) noted, the magnitude of the $D$ statistic from proportional hazards models will generally be smaller than $R^{2}$ statistics from regressions that predict turnover probability. This is a result of the dependent variable in proportional hazards being turnover conditional on tenure. That is, we are attempting to explain turnover probability at specific times, not simply whether turnover occurred (Peters \& Sheridan, 1988). As a point of reference, however, Sheridan's (1992) turnover study with proportional hazards modeling accounted for less variance $(D=.09)$ than the present study $(D=.17) . D=\chi^{2} \div\left(n-k=\chi^{2}\right)$, where $n$ is the sample size and $k$ is the number of variables (Hintze, 1989). 
Table 2

Comparison of Proportional Hazard Regression Analyses of Voluntary Turnover for Continuous and Categorical Performance Measures

\begin{tabular}{|c|c|c|c|c|}
\hline \multirow[b]{2}{*}{ Independent Variable } & \multicolumn{4}{|c|}{ Continuous performance } \\
\hline & Baseline & Linear & Quadratic & $\begin{array}{l}\text { Categorical } \\
\text { performance }\end{array}$ \\
\hline Promotions & $0.442^{\star \star \star \star}$ & $0.434^{\star \star \star \star}$ & $0.441^{\star \star \star \star}$ & $0.397^{\star \star \star \star}$ \\
\hline Salary growth & $-0.716^{\star \star \star *}$ & $-0.647^{\star \star \star *}$ & 0.024 & $-0.602^{\star \star * *}$ \\
\hline Average performance & & $-0.363^{\star \star \star \star}$ & 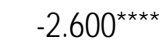 & \\
\hline Salary Growth x Performance & & & 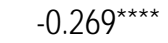 & \\
\hline Squared average performance & & & $0.477^{\star \star \star *}$ & \\
\hline Average performance & & & & \\
\hline 1.0 & & & & $1.572^{\star \star \star \star}$ \\
\hline 1.5 & & & & $0.293^{*}$ \\
\hline 2.0 & & & & $0.574^{\star \star \star \star}$ \\
\hline 2.5 & & & & $-0.270^{\star \star \star}$ \\
\hline 3.0 & & & & \\
\hline 3.5 & & & & $-0.344^{\star \star \star}$ \\
\hline 4.0 & & & & 0.126 \\
\hline 4.5 & & & & 0.014 \\
\hline 5.0 & & & & $1.701^{\star \star \star \star}$ \\
\hline Change in model chi-square & & $45.792^{\star \star \star *}$ & $112.307^{\star \star \star \star}$ & $167.115^{\star \star \star \star}$ \\
\hline$D$ & .1493 & .1557 & .1711 & .1724 \\
\hline
\end{tabular}

Note. Equations also include salary level, marital status, and age. Performance ranges from $1=$ lowest to $5=$ highest. $\quad{ }^{*} p<.10 \quad{ }^{* \star *} p<.01{ }^{* \star *} p<.001$

To illustrate and interpret the performance-turnover curvilinearity, we plotted survival probabilities on the basis of the proportional hazards model incorporating categorical performance. As Figure 1 indicates, the performance-turnover relationship does indeed appear to be curvilinear. Note that the vertical axis represents survival probability and is thus equal to 1 - turnover probability. For comparison purposes, the relationship was plotted for three separate tenure levels. The probability of remaining employed throughout each of the tenure levels initially increases with performance, but then it leveled off. In all three scenarios, survival probabilities sharply decreased in the highest performance rating category. Furthermore, comparisons with plots of the predicted values from the equations imposing linearity revealed that the most dramatic differences between linear and nonlinear representations were at the highest performance rating category. In summary, these findings strongly support the curvilinear performance-turnover relationship described in Hypothesis 1. 


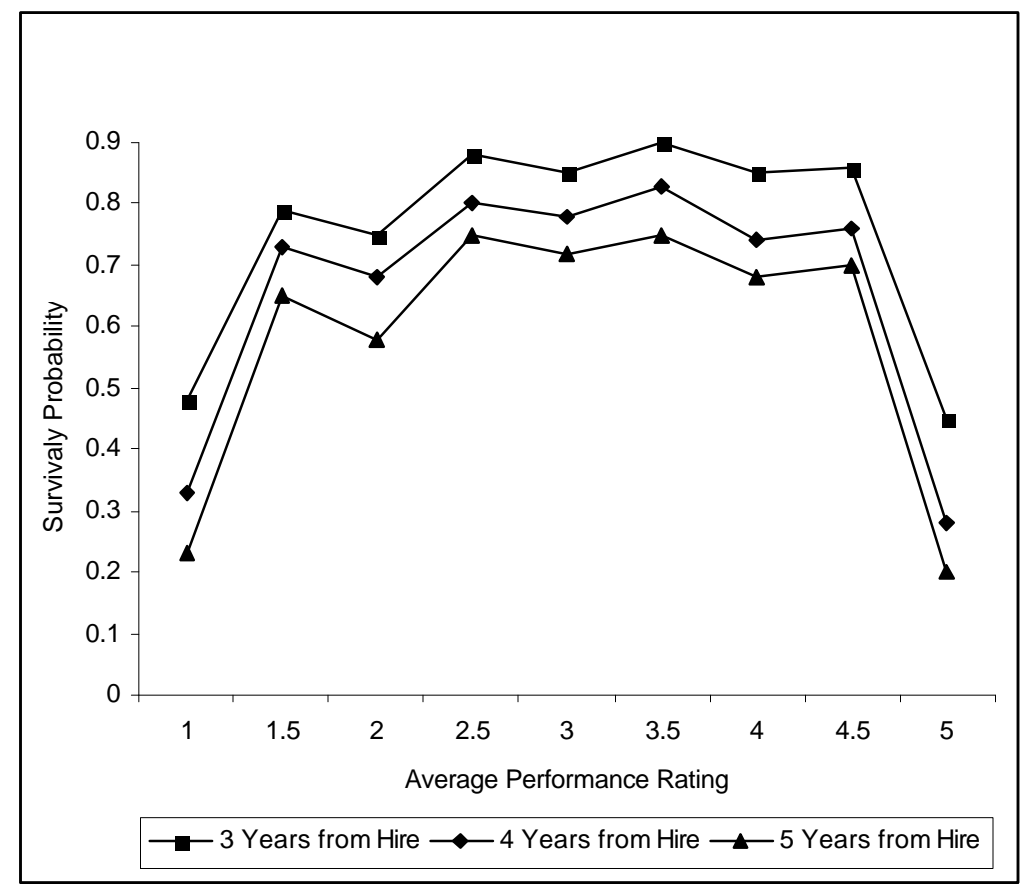

Figure 1. Survival Probability $x$ Average Performance Rating $x$ Tenure.

One possible explanation for this finding would be a weak relationship between performance and salary growth, such that top performers left because of high movement desirability brought on by inadequate salary growth. Table 3 reports two sets of estimates from regressing salary growth on performance. ${ }^{3}$ The first equation treats the relationship between salary growth and performance as linear and depicts a significant positive association between the two. However, the second equation uses performance categories to allow for a possible nonlinear relationship. Although the overall fit represented by the $R^{2}$ is similar in the two equations, the categorical performance model allowed a closer examination of differences in the relationship between pay growth and performance at various performance levels. This was an advantage, given our particular interest in high performer turnover. The predicted values from the categorical performance model, as well as those from the linear performance model, are plotted in Figure 2. When the relationship is free to be nonlinear, these values indicate that

\footnotetext{
${ }^{3}$ In the Table 3 regressions of salary growth on performance, we did not include the promotions variable because we were interested in assessing the total effect of performance on salary growth, including any indirect effect that would be mediated by promotions. Inclusion of the promotions term did not change the overall conclusion from the table. In the turnover models that incorporate analyses of salary growth and promotions as main effects and moderators, we included both terms in order to separate their effects (e.g., the effect of promotions net of the effect of salary growth). Conceptually, it may be more precise to exclude promotions when investigating salary growth because our concern is on the total effect of salary growth, even if some of the effect is due to salary growth attributable to promotion. We did conduct such analyses, and compared to the models reported here, we found little difference regarding salary growth's main and moderating effects on turnover. In the interests of parsimony, throughout the article, we have presented only the full models that incorporate both terms.
} 
salary growth increases $151 \%$ more quickly (i.e., the slope is 2.5 times greater) between performance levels 1.0 and 2.5 than between performance levels 2.5 and 5.0. Moreover, salary growth increases $91 \%$ more rapidly between performance levels 1.0 and 3.5 than between levels 3.5 and 5.0. That is, salary growth increases at a greater rate for low performers than for high performers. This fact may help to explain the diminishing top performer survival probabilities depicted in Figure 1.

As a formal test of the possible interaction between salary growth and performance (Hypothesis 2), two equations were estimated. The first (see Table 2) contained only main effects for categorical performance, salary growth, promotions, and the controls. The second equation added eight terms for the cross products of salary growth and the performance categories (see Table 4). Comparison of the two equations is an overall significance test of the interaction of a continuous and categorical variable (Aiken \& West, 1991). This joint test revealed a statistically significant improvement in the model, meaning that across performance levels, there is an overall difference in the salary growth effects on turnover probability. Furthermore, analysis of the continuous performance model in Table 4 supported the emergence of salary growth as a moderator of the curvilinear performance-turnover relationship. The cross product of squared performance and salary growth was significant, indicating that the parabolic relationship between performance and turnover depends on salary growth.

Table 3

Regression Analyses of Average Annual Salary Growth on Continuous and Categorical Average Performance Ratings

\begin{tabular}{|c|c|c|c|c|}
\hline \multirow[b]{2}{*}{ Independent variable } & \multicolumn{2}{|c|}{ Equation 1} & \multicolumn{2}{|c|}{ Equation 2} \\
\hline & Coefficient & SE & Coefficient & SE \\
\hline Average performance & $0.754^{\star \star \star \star}$ & .032 & & \\
\hline \multicolumn{5}{|l|}{ Average performance } \\
\hline 1.0 & & & $-1.789^{\star \star \star \star \star}$ & 0.196 \\
\hline 1.5 & & & $-1.416^{\star \star \star \star}$ & 0.156 \\
\hline 2.0 & & & $-0.769^{\star \star * *}$ & 0.057 \\
\hline 2.5 & & & 0.032 & 0.059 \\
\hline \multicolumn{5}{|l|}{3.0} \\
\hline 3.5 & & & $0.516^{\star \star \star \star}$ & 0.069 \\
\hline 4.0 & & & $0.705^{\star \star \star \star}$ & 0.092 \\
\hline 4.5 & & & $0.523^{\star *}$ & 0.223 \\
\hline 5.0 & & & $1.241^{\star \star \star \star}$ & 0.313 \\
\hline Salary level & $0.017^{\star \star \star \star}$ & 0.001 & $.017^{\star \star \star \star}$ & 0.002 \\
\hline Marital status & $-0.272^{\star \star \star \star}$ & 0.045 & $-.273^{\star \star \star \star}$ & 0.045 \\
\hline Age & $-0.062^{\star \star \star *}$ & 0.003 & $-.061^{\star \star \star *}$ & 0.003 \\
\hline Intercept & $1.634^{\star \star \star \star}$ & 0.145 & $3.771^{\star \star \star \star}$ & 0.125 \\
\hline$R^{2}$ & \multicolumn{2}{|c|}{.19} & \multicolumn{2}{|c|}{.20} \\
\hline
\end{tabular}


In terms of interpreting the categorical performance model's interaction terms, the .63 coefficient for the cross product of salary growth and performance category 1.0, for example, means that membership in performance category 1.0 rather than 3.0 (the omitted category) results in an increase of .631 in the salary growth coefficient. Note that because all of the salary growth effects are negative, the increase results in a negative effect of smaller magnitude for performance category 1.0. For a more intuitively informative examination of the nature of the interaction between salary growth and performance, we used the procedure outlined in Aiken and West (1991) for evaluating the effects of a continuous predictor conditional on a certain value of a categorical predictor. To assess the entire salary growth effect at each performance level, the main effect from the interaction model in Table 4 is added to the performance specific effect in the cross product term (see Aiken \& West, 1991, for calculation of significance levels). As the coefficients in Table 5 indicate, the relationship between salary growth and turnover is significant and negative at all performance levels but clearly increases in magnitude as performance increases and has the greatest magnitude at the top two performance categories, thus supporting Hypothesis 2. The salary growth effects on turnover probability for employees at the 4.5 and 5.0 performance levels are $30 \%$ and $39 \%$ larger, respectively, than the next largest effect (performance $=3.0$ ) and are over twice as large as the average effect of the other seven performance levels. Moreover, the correlation between performance levels and the salary growth effects was $.95(p<.001)$, also supporting Hypothesis 2.

To illustrate this moderating effect of salary growth on the performance-turnover relationship, we computed survival probabilities throughout the performance range from the categorical interaction model in Table 4 at three levels of salary growth (i.e., at salary growth's mean, and at plus and minus one standard deviation) (see Figure 3). In agreement with the coefficients reported in Table 5, and readily visible in the distance between the plotted survival probabilities for high and low salary growth, the negative effect of salary growth on turnover is greatest at high performance levels. The more pronounced curvilinearity in the low salary growth condition, which was predicted in Hypothesis 2, implies that failure to pay top performers for that performance results in substantial loss of these employees. In contrast, high pay for performance helps to retain the top performers at rates similar to the relatively low turnover of average performers. We found further support for the apparent relationship depicted in Figure 3 by using Aiken and West's (1991) technique for testing the difference between predicted values at any two levels of the interaction term's categorical predictor for a specified value of the term's continuous predictor. When salary growth was low, turnover probability for top performers (Performance Category 5.0) was statistically larger than for all other performance levels except 
performance category 1.0. However, when salary growth was high, top performer turnover probability was not statistically different from any other level except category 1.0. Similar conclusions regarding the moderating effect of salary growth are evident in plots from the continuous performance interaction model (these plots are available from the authors upon request).

The lack of research on the effect of promotions prompted our third hypothesis, which proposed that average annual promotions would increase turnover. Whereas the correlation in Table 1 between promotions and turn over was significantly negative, once the effects of salary growth and the other variables were partialed out in the proportional hazards regression models (i.e., in both the continuous and categorical performance models), promotions did in fact exhibit a positive relationship with turnover (see Table 2). Thus, Hypothesis $3 a$ and our supposition of promotions contributing to employee viability on the external market were supported.

The promotions coefficient (e.g., 397 in the categorical performance model) can be interpreted in a manner analogous to ordinary least squares regression (Morita et al., 1993). Assume 2 employees were equal in all respects except that Employee 1 had averaged one promotion per year, and Employee 2 had no promotions. Because their respective hazard functions would differ only by the exponentiated promotions variable value, Employee 1 would be more likely to leave by a factor of $\exp [(.397) \times(1-0)]$. Hence, controlling for the other variables, increasing average promotions from 0 to 1 increases turnover likelihood by a factor of 1.49. Employee 1 would be about $50 \%$ more likely to leave than Employee 2 , all else remaining equal. 
Table 4

Proportional Hazard Regression Analyses of Voluntary Turnover on Interaction Models for Continuous and Categorical Performance

\begin{tabular}{|c|c|c|c|c|}
\hline \multirow[b]{2}{*}{ Independent variable } & \multicolumn{2}{|c|}{ Continuous performance model } & \multicolumn{2}{|c|}{ Categorical performance model } \\
\hline & Salary growth & Promotions & Salary growth & Promotions \\
\hline Salary level & 0.000 & -0.003 & -0.001 & -0.004 \\
\hline Age & $-0.059 * * * *$ & $-0.056^{\star \star \star *}$ & $-0.056^{\star \star * *}$ & $-0.056^{\star \star \star *}$ \\
\hline Marital status' & $-0.197^{\star \star \star}$ & $-0.201^{\star \star \star}$ & $-0.209^{\star \star \star \star}$ & $-0.202^{\star \star *}$ \\
\hline Salary growth & 0.314 & $-0.654^{\star \star \star \star}$ & $-0.893^{\star \star \star \star}$ & $-0.619 * \star \star \star$ \\
\hline Promotions & $0.473^{\star \star \star \star}$ & $3.203^{\star \star \star \star}$ & $0.383^{\star \star \star *}$ & 0.153 \\
\hline Average performance & $-2.541^{\star \star \star \star}$ & $-2.047^{\star \star \star \star}$ & & \\
\hline Squared average performance & $0.553^{\star \star}$ & $0.352^{\star \star \star \star}$ & & \\
\hline Average performance & & & & \\
\hline 1.0 & & & $1.183^{\star \star \star \star}$ & 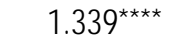 \\
\hline 1.5 & & & -0.210 & 0.028 \\
\hline 2.0 & & & 0.083 & 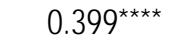 \\
\hline 2.5 & & & $-0.657^{\star \star \star \star}$ & $-0.356^{\star \star \star}$ \\
\hline 3.0 & & & & \\
\hline 3.5 & & & $-0.628^{\star *}$ & $-0.348^{*}$ \\
\hline 4.0 & & & 0.046 & $-0.452^{\star \star}$ \\
\hline 4.5 & & & 0.486 & 0.082 \\
\hline 5.0 & & & $2.275^{\star \star \star \star}$ & $1.869^{\star \star \star \star}$ \\
\hline Cubed average performance & -0.020 & & & \\
\hline Cubed salary growth & $0.007^{\star \star \star \star}$ & & & \\
\hline Salary Growth x Performance & $-0.633^{\star \star \star \star}$ & & & \\
\hline Salary Growth x Squared Performance & $0.071^{\star *}$ & & & \\
\hline Promotions x Performance & & $-1.549 * \star$ & & \\
\hline Promotions x Squared Performance & & 0.176 & & \\
\hline Salary Growth $x$ Performance & & & & \\
\hline 1.0 & & & $0.631^{\star \star \star *}$ & \\
\hline 1.5 & & & $0.609^{\star \star \star}$ & \\
\hline 2.0 & & & $0.421^{\star \star \star \star}$ & \\
\hline 2.5 & & & $0.278^{\star \star \star}$ & \\
\hline 3.0 & & & & \\
\hline 3.5 & & & $0.221^{*}$ & \\
\hline 4.0 & & & 0.104 & \\
\hline 4.5 & & & -0.267 & \\
\hline 5.0 & & & -0.351 & \\
\hline Promotions x Performance & & & & \\
\hline 1.0 & & & & $1.146^{\star \star}$ \\
\hline 1.5 & & & & $1.208^{\star}$ \\
\hline 2.0 & & & & $0.525^{\star \star}$ \\
\hline 2.5 & & & & 0.236 \\
\hline 3.0 & & & & \\
\hline 3.5 & & & & 0.052 \\
\hline 4.0 & & & & $-1.109^{*}$ \\
\hline 4.5 & & & & -0.370 \\
\hline 5.0 & & & & -0.313 \\
\hline Change in chi-square & $56.74^{\star \star \star \star}$ & $22.86^{\star \star \star \star}$ & $57.47^{\star \star \star \star}$ & $18.85^{\star \star}$ \\
\hline D & .1859 & .1675 & 1803 & 1752 \\
\hline
\end{tabular}

Note. In the original test for curvilinearity under the continuous performance condition, a Performance $x$ Salary Growth interaction term was included because the two terms are correlated such that performance squared might otherwise pick up some of the interaction's effect on turnover. Because there was no reason to include that interaction term in the test of the interaction between performance squared and promotions and because the main effects models had to be nested within interaction models for valid chi-square comparisons, the promotions and the salary growth interaction models was compared with different baselines. In the categorical performance condition, the lama baseline model was nested within both interaction reels.

$$
\text { a1 }=\text { married } \quad{ }^{*} p<.10 .{ }^{* \star} p<.05 .{ }^{* \star *} p<.01 .{ }^{* \star * \star} p<.001 .
$$




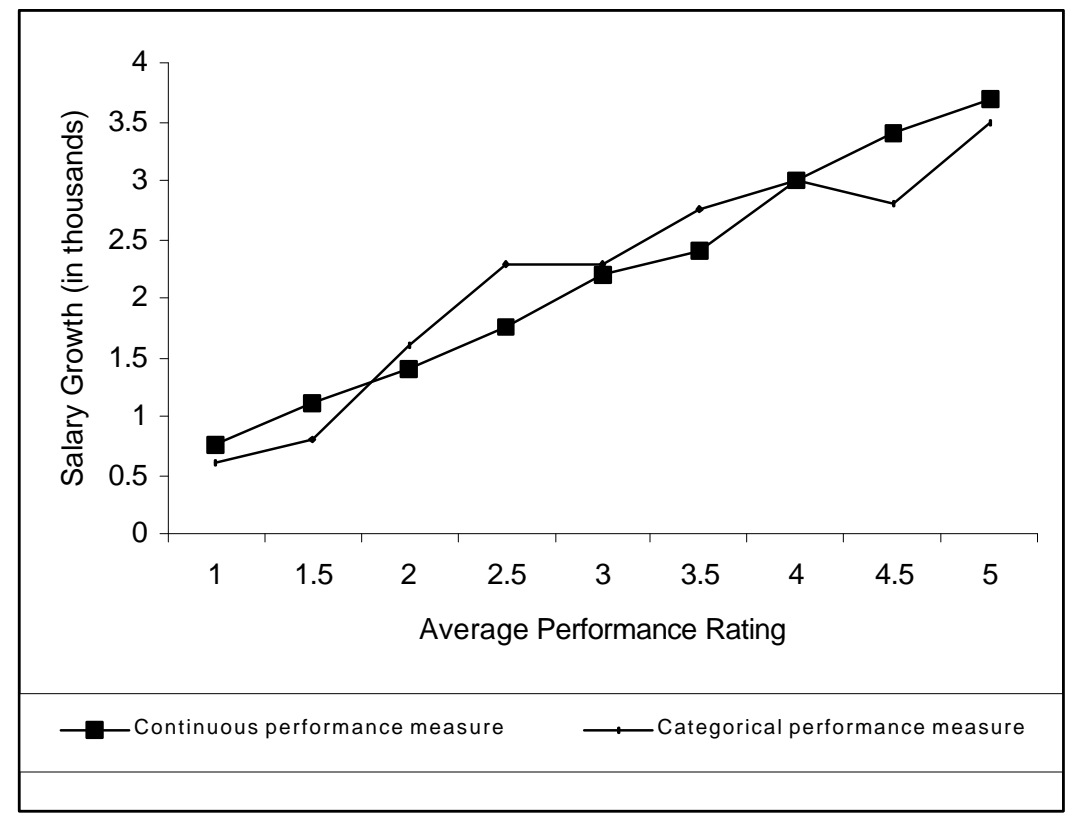

Figure 2: Salary growth as a function of continuous and categorical performance measures.

Table 5

Proportional Hazard Regressions of Voluntary Turnover on Average Annual Salary Growth and Average Annual Promotions, for each Average Performance Category

\begin{tabular}{|c|c|c|c|}
\hline \multicolumn{4}{|c|}{ Coefficient } \\
\hline $\begin{array}{c}\text { Average } \\
\text { performance level }\end{array}$ & Salary growth & Promotions & $\begin{array}{c}\text { No. of } \\
\text { observations }\end{array}$ \\
\hline 1.0 & $-0.26^{*}$ & $1.30^{\star \star}$ & 60 \\
\hline 1.5 & $-0.29^{*}$ & $1.36^{\star \star}$ & 97 \\
\hline 2.0 & $-0.47^{\star \star \star \star}$ & $0.68^{\star \star \star \star}$ & 1,171 \\
\hline 2.5 & $-0.62^{\star \star \star \star}$ & $0.39 *$ & 1,090 \\
\hline 3.0 & 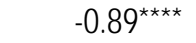 & 0.15 & 1,667 \\
\hline 3.5 & $-0.67^{\star \star \star \star}$ & 0.20 & 672 \\
\hline 4.0 & 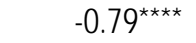 & -0.96 & 317 \\
\hline 4.5 & $-1.16^{\star \star \star}$ & -0.22 & 46 \\
\hline 5.0 & $-1.24^{\star \star \star \star}$ & -0.16 & 23 \\
\hline
\end{tabular}

Note. At each performance category, the equation includes salary growth, promotions, salary level age, and marital status. Performance ranges from $1=$ lowest to $5=$ highest. ${ }^{*} p<.10 .{ }^{* *} p<.05 .{ }^{* \star * \star} p<.001$.

Although this interpretation would seem to imply that assuming salary growth is retained, limiting promotions might be a viable strategy for reducing turnover, analysis of the promotions-performance interaction suggests an alternative explanation. In the categorical performance case, addition of the eight performance by promotions cross product terms to the Table 2 proportional hazards model resulted in a statistically significant improvement in model fit (see Table 4). This indicates that across performance levels, there is a significant overall difference in effects of promotions on turnover probabilities. Similar to the approach taken for 
the salary growth moderator to more closely examine the nature of the interaction we evaluated the effects of promotions conditional on performance category. As indicated by the Table 5 promotions coefficients, the relationship between promotions and turnover is positive and significant for lower performers, is strongest at the lowest two performance categories, and is not different from zero for the top five performance categories. The correlation between performance levels and the effect of promotions on turnover probability is $-.87(p<.01)$. In summary, the positive effect of promotions on turnover increases as performance decreases, providing support for Hypothesis $3 b$.

To better illustrate how promotions moderated the performance-turnover relationship, we used the estimates from the interaction model in Table 4 to compute survival probabilities for high promotions (1 SD above the mean), mean level, and low promotions (set at zero, which was .93 of $1 S D$ below the mean; see Figure 4). As indicated by the distances between plotted survival probabilities for employees with high and low promotions (see Figure 4), at the higher levels of performance promotions appear to make little difference in turnover decisions. However, as indicated by the substantially larger distance between the plots for the lowest performance categories and the subsequent more pronounced curvilinearity in the high promotions condition in Hypothesis 3b, the positive effect of promotions on turnover probability is strongest for low performers. Thus, the predicted survival probabilities reinforce the conclusions from the Table 5 coefficients.

For the models that used performance as a continuous variable, the addition of the Performance $X$ Promotion interaction terms yielded a significantly better fit to the data than in the main effects model. However, the Linear Promotion X Performance interaction appeared to "carry" the majority of the effect, as this term was significant but the Promotions $X$ Squared performance term was not $(p=.13)$. Because this model is constrained to a parabolic relationship, however, it does not necessarily contradict the nonlinear interaction evidence from the categorical performance analyses. Yet, this result, coupled with the significant but relatively small increase in variance explained by the categorical model's cross product terms, suggests that the overall support for the Promotions $X$ Performance interaction may be somewhat tentative.

\section{Discussion}

The present findings suggest that the relationship between employee performance and voluntary employee turnover is curvilinear; such that low and high performers exhibit greater turnover than average performers. Given the recent meta-analytic support for curvilinearity 
(Williams \& Livingstone, 1994) and our results, which are based on a sample size far exceeding the total sample for the meta-analytic curvilinearity test, we suggest that there is strong evidence that Jackofsky's (1984) curvilinear conceptualization accurately describes the underlying relationship between job performance and voluntary turnover. The growing evidence of a negative linear performance-turnover relationship should be interpreted in light of the fact that in the vast majority of cases, curvilinearity was not investigated. We join Schwab (1991) and Williams and Livingstone (1994) in maintaining that researchers should regularly test for the presence of curvilinearity in studies of job performance and turnover.

Our results also indicate that performance-turnover research benefits not only by allowing for curvilinearity but also by examining contextual factors that can moderate this relationship. Consequently, perhaps the most important result from this study concerns the moderating influence of salary growth. We found that low salary growth resulted in a more pronounced curvilinear relationship, relative to the high salary growth condition, as top performer turnover probabilities approximated the high turnover tendencies of poor performers. Conversely, because the negative effect of salary growth on turnover probability increased in magnitude as performance increased, paying for high performance defused this tendency as high performer turnover probabilities resembled the relatively low turnover tendencies of average employees.

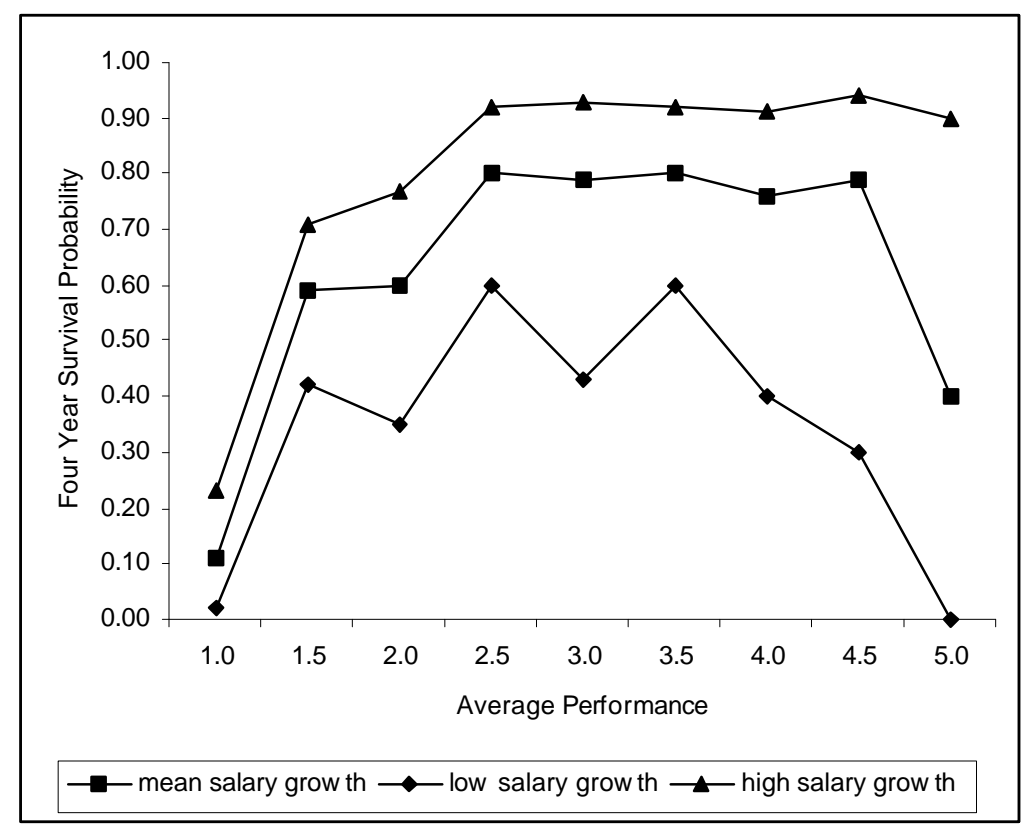

Figure 3: Survival Probability X Average Performance Rating X Salary Growth. 
The greatest differences in retention under conditions of low and high salary growth were by far in the top two performance categories. We contend that the fate of these few employees is disproportionately important to the organization. Top performers are of value not only for their present and short-term future performance value alone but also for the selection pool from which future firm leaders will be chosen. Precisely because there are so few indispensable firm members or "franchise players" that can affect the success of the entire organization, it is important to maximize selection pool quality not only to increase future leader quality (on average) but also to maximize the probability of finding an exceptional, differencemaking executive. Similarly, consider the importance of retaining a top medical researcher who might someday discover a breakthrough vaccine. Tomorrow's stars and perhaps even franchise players may be among today's few top performers; their retention, at least in part, appears to depend on paying them according to their performance.

Moreover, motivational theory indicates that a firm's financial treatment of the few top performers seems certain to have implications for the motivation and performance of the remaining employees. Why should these workers strive to perform better when they can see, either through direct knowledge of top performer pay or through attributions made from top performer turnover that such performance improvements will not be sufficiently rewarded? For example, tournament theory predicts that such a situation (i.e., the perception of a low payoff for top performance) will result in relatively low motivation and performance among those with the ability to raise their performance levels. Similar predictions would follow from expectancy and equity theories. To the extent that such motivational effects were present in our sample, the results regarding high performer turnover could be understated. That is, some of the average performers would actually be discouraged top performers, thus representing a type of unmeasured high performer turnover and resulting in lower power in our hypothesis testing. In summary, retaining talent is a fundamental tenet of compensation strategy, and, according to our data, pay growth commensurate with performance appears to be one effective approach toward meeting that goal. 


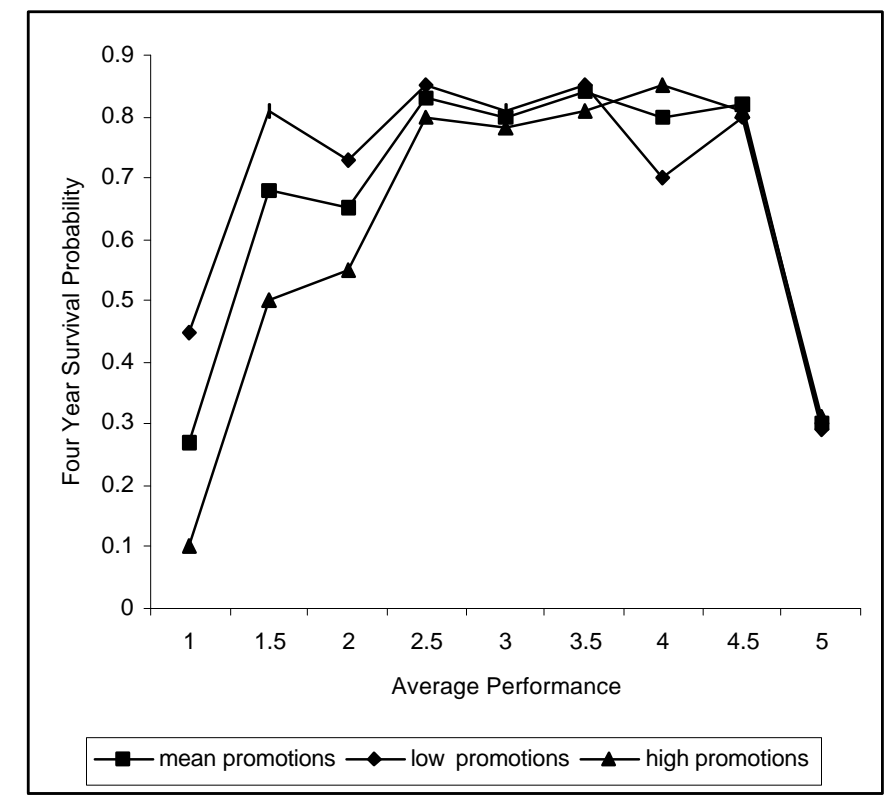

Figure 4. Survival Probability X Average Performance Rating X Promotions

In addition to results regarding salary growth, we (to our knowledge) found that the first positive effect of promotions on turnover (presumably by being the first researchers to control for pay growth), thus supporting the visibility and signaling concepts in the organizational (e.g., Schwab, 1991) and labor economic (e.g., Lazear, 1986) literatures. Although promotions also were found to be a significant moderator, the relatively small additional variance explained by the interaction and the failure of the continuous performance model to confirm the categorical model's significant interaction make resultant implications somewhat tentative. The largest effect of promotions was a facilitation of low performer turnover, which resulted in a more pronounced curvilinear performance turnover relationship. Because such elements as training, professional certifications, or skill-based pay also might result in relatively concrete credentials for the employee, it may be that similar to the promotions scenario, these elements facilitate low performer ease of movement (i.e., through visibility and signaling) and subsequent turnover while having little effect on high performer turnover. Moreover, we might expect lower performers to be quicker to separate upon receiving externally visible credentials, because of a past without such ability indicators and the expectation that future indicators may not be forthcoming. Finally, the lack of a promotions effect for high performers bodes well for flatter organizations, where one fear is that promotional bottlenecks will precipitate high performer turnover. The inference from our results is that a lack of promotions should not be a problem, as long as those that perform well are paid accordingly. On the other hand, the uncoupling of promotions and pay growth may well yield high performer turnover if promotions are given 
without being accompanied by appropriate salary increases (Johnson, Griffeth, Burton, \& Carson, 1993).

From a theoretical perspective, the results of this study have several applications. The finding of curvilinearity supports Jackofsky (1984). Moreover, our contextual approach allows for certain inferences regarding curvilinearity and the turnover determinants first set forth by March and Simon (1958). That is, incorporating contextual factors, such as pay growth and promotions into Jackofsky's framework, can illustrate how movement ease and desirability can appear to lead to different degrees of and even the absence of curvilinearity. For example, Jackofsky's implicit assumption that high performers' ease of movement will not be offset by lower movement desirability appeared to hold completely true only when pay and performance were not tightly coupled for top performers. When pay and performance were strongly linked, the finding that top performer turnover probability remained low (i.e., less curvilinearity; see Figure 3) suggests that the high movement ease enjoyed by high performers can be negated by low movement desirability. Additionally, we speculate that with salary growth effects removed, promotions may still have created somewhat lower movement desirability because of unmeasured elements such as challenge, positive reinforcement, and relief of boredom. However, our findings suggest that any promotion driven decreases in movement desirability for low performers were overcome by increases in actual and or perceived ease of movement, resulting in more turnover and greater curvilinearity

Moderators other than those in the present study would shed further light on the performance-turnover theoretical modeling that we espouse, as well as being of interest from a practical perspective. Certainly the labor market seems to have implications for performance specific ease of movement and turnover (Carsten \& Spector, 1987; Gerhart, 1990b), although current evidence is not particularly supportive (Williams \& Livingstone, 1994). Unfortunately, we were unable to adequately assess the labor market conditions most relevant to our sample. External pay equity might also moderate the performance-turnover relationship. Indeed, Schwab (1991) in part attributed a positive relationship between performance and turnover for tenured university faculty members to the higher pay level available in the external market. Macro-level organizational variables should also be investigated. Accordingly Sheridan (1992) found a significant interaction between organizational culture and performance in the investigation of turnover: Other possible macro-level moderators include diversification, industry, and downsizing.

Future research with data from multiple organizations would permit an examination of whether firm differences in contextual factors such as the performance contingency of pay 
correspond to differences in the performance levels of leavers. Earlier research (Gerhart \& Milkovich, 1990) clearly demonstrated that organizations' pay strategies differ significantly, particularly as to how pay is delivered (e.g., relative emphasis on base and bonus pay). Thus, it seems likely that pay-performance relationships may differ similarly. It would be useful to determine whether the key implication of the present study-that stronger pay for performance relationships substantially decrease turnover among high performers-could be replicated with that type of multiple organization data set.

In summary, this study provided evidence for aspects of the performance-turnover relationship that (a) have received limited empirical examination in individual studies (i.e., reward contingency as a moderator and curvilinearity); (b) have been suggested only at the conceptual level (i.e., promotions as having a positive effect on turnover); (c) have not been previously addressed (i.e., promotions as a moderator); and (d) have not been previously studied together (i.e., pay growth and promotions as moderators of an underlying curvilinear relationship). Although a multiple item performance measure would have been preferable to our single-item measure, we suggest that our large sample and actual measures of turnover, pay growth, and promotions permitted what we believe to be the most comprehensive investigation of the curvilinear performance-turnover relationship to date. Because we dealt with all exempt hires in a large corporation, our results may have greater bottom-line implications than studies of lower level employees and may be more generalizable than studies of a single job type. 


\section{References}

Aiken, L.S., \& West, S. G. (1991). Multiple regression: Testing and interpreting interactions. Newbury Park, CA: Sage.

Andersen, P K. (1982). Testing goodness of fit of Cox's regression and life model. Biometrics, $38,67-77$.

Bernhardt, D., \& Scoones, D. (1993). Promotion, turnover, and preemptive wage offers. American Economic Review, 83, 771-791.

Birnbaum, D., \& Somers, M. J. (1993). Fitting job performance into turnover model: An examination of the job performance turnover relationship and a path model. Journal of Management, 19, I-11.

Boudreau, J. W. (1992). Utility analysis for decisions in human resource management. In M. D. Dunnette \& L. M. Hough (Eds.), Handbook of industrial and organizational psychology (2nd ed., Vol. 2, pp. 621-745). Palo Alto, CA: Consulting Psychologists Press.

Boudreau, J. W., \& Berger, C. J. (1985). Decision-theoretic utility analysis applied to employee separations and acquisitions [Monograph]. Journal of Applied Psychology, 70, 581-612.

Bycio, P., Hackett, R. D., \& Alvares, K. M. (1990). Job performance and turnover. A review and meta-analysis. Applied Psychology: An International Review, 61, 468-472.

Carsten, J. M., \& Spector, P E. (1987). Unemployment, job satisfaction, and employee turnover. A meta-analytic test of the Muchinsky model. Journal of Applied Psychology, 72, 374-381.

Cascio, W.F. (1994). Costing human resources (3rd ed.). Boston: Kent.

Cohen, J., \& Cohen, P (1983). Applied multiple regression correlation analysis for the behavioral sciences (2nd ed.). Hillsdale, NJ: Erlbaum.

Cortina, J. M. (1993). Interaction, nonlinearity, and multicollinearity: Implications for multiple regression. Journal of Management, 19, 915-922.

Cox, D. R. (1972). Regression models and life tables [with discussion]. Journal of the Royal Statistical Society B, 34, 187-220.

Dalton, D. R., Todor W D., \& Krackhardt, D. M. (1982). Turn over overstated: The functional taxonomy. Academy of Management Review, 7, 117-123.

Dipboye, R. L. (1985). Some neglected variables in research on discrimination in appraisals. Academy of Management Review, 10, 116-127.

Dreher. G. F (1982). The role of performance in the turnover process. Academy of Management Journal, 25, 137-147.

Ferris, G. R, Buckley, M. R, \& Allen, G. M. (1992). Promotion systems in organizations. Human Resource Planning, 15,47-68. 
Fichman, M. (1989). Attendance makes the heart grow fonder. A hazard rate approach to modeling attendance. Journal of Applied Psychology, 74, 325-335.

Forbes, J. B., \& Piercy, J. E. (1991). Corporate mobility and paths to the top: Studies for human resource and management development specialists. Westport, CT Quorum Books.

Forbes, J. B., \& Wertheim, S. E. (1995). Promotion, succession, and career systems. In G. R. Ferris, S. D. Rosen, \& D. T Barnum (Eds.), Handbook of human resource management (pp. 494-510). Cambridge, MA: Blackwell.

Garelik, M. (1984). Hay compensation conference business/ economic overview. In Hay Compensation Conference Proceedings (pp. 7-15). Philadelphia: The Hay Group.

Gerhart, B. (1990a). Gender differences in current and starting salaries: The role of performance, college major, and job title. Industrial and Labor Relations Review, 43, 418-433.

Gerhart, B. (1990b). Voluntary turnover and alternative job opportunities. Journal of Applied Psychology, 75, 467-476.

Gerhart, B., \& Milkovich, G. T. (1989). Salaries, salary growth, and promotions of men and women in a large private firm. In R. T. Michael, H. Hartmann, \& B. O'Farrell (Eds.), Pay equity: Empirical inquiries (pp. 23-43). Washington, DC: National Academy Press.

Gerhart, B., \& Milkovich, G. T. (1990). Organizational differences in managerial compensation and financial performance. Academy of Management Journal, 33, 663-691.

Gerhart, B \& Milkovich, G. T (1992). Employee compensation: Research and practice. In M. D. Dunnette \& L. M. Kough (Eds.), Handbook of industrial and organizational psychology (2nd ed., Vol. 3, pp. 481-569). Palo Alto, CA: Consulting Psychologists Press.

Harrison, D. A., \& Hulin, C. L. (1989). Investigations of absenteeism: Using event history models to study the absence-taking process. Journal of Applied Psychology, 74, 300-316.

Hay Group. (1994 ). The Hay Report: Compensation and benefits strategies for 1995 and beyond Philadelphia: Author.

Heneman, R. L. (1990). Merit pay research. In K. M. Rowland \& G. R. Ferris (Eds.). Research in Personnel and Human Resources Management (Vol. 8, pp. 203-263). Greenwich, CT. JAI Press.

Hintze, J. L. (1989). SOLO statistical system: Version 3.0 survival analysis. Los Angeles: BMDP Statistical Software.

Hollenbeck, J. R., \& Williams, C. R. (1986). Turnover functionality versus turnover frequency: A note on work attitudes and organizational effectiveness. Journal of Applied Psychology, 71, 606-611.

Jackofsky E. F (1984). Turnover and job performance: An integrated process model. Academy of Management Review, 9, 74-83. 
Jackofsky, E. F, Ferris, K. R., \& Breckenridge, B. G. (1986). Evidence for a curvilinear relationship between job performance and turnover: Journal of Management, 12, 105-111.

Johns, G. (1989). Performance and turnover cognitions among managers. Canadian Journal of Administrative Science, 6, 37-42.

Johnston, M. W, Griffeth, R. W, Burton, S., \& Carson, P. P. (1993). An exploratory investigation into the relationships between promotion and turnover. A quasi-experimental longitudinal study. Journal of Management, 19, 33-49.

Judge, T A., 8r. Watanabe, S. (1995). Is the past prologue? A test of Ghiselli's hobo syndrome. Journal of Management, 21, 211-229.

Kalbfleisch, J. D., \& Prentice, R. L. (1980). The statistical analysis of failure time data. New York: Wiley.

Kelley, H. H. (1972). Causal schemata and the attribution process. In E. E. Jones, D. E. Kanouse. H. H. Kelley. R. E. Nisbett, S. Valins, \& B. Weiner (Eds.), Attribution: Perceiving the causes of behavior. Morristown, NJ: General Learning Press.

King, L. M., Hunter, J. E., \& Schmidt, F L. (1980). Halo in a multi-dimensional forced choice performance evaluation scale. Journal of Applied Psychology, 65, 507-516.

Lawler, E. E. (1981). Pay and organizational development. Reading, MA: Addison-Wesley.

Lawler, E. E. (1989). Pay for performance: A strategic analysis. In L. R. Gomez-Mejia (Ed.), Compensation and benefits (pp. 136-181). Washington, DC: Bureau of National Affairs.

Lazear, E. P (1986). Raids and offer matching. In R. G. Ehrenberg (Ed.), Research in Labor Economics (Vol. 8, pp. 141-165). Greenwich, CT JAI Press.

March, J. G., \& Simon, H. A. (1958). Organizations. New York: Wiley.

McEvoy, G. M., \& Cascio. W F (1987). Do good or poor performers leave? A meta-analysis of the relationship between performance and turnover. Academy of Management Journal, 30. 744-762.

Milgrom, P, \& Oster, S. (1987). Job discrimination, market forces, and the invisibility hypothesis. Quarterly Journal of Economics, 102, 453-476.

Milkovich, G. T, \& Newman, J. M. (1993). Compensation. Homewood, IL: Irwin.

Morita, J. G., Lee, T. W., \& Mowday, R T (1989). Introducing survival analysis to organizational researchers: A selected application to turnover research. Journal of Applied Psychology, $74,280-292$.

Morita, J. G., Lee, T. W., \& Mowday, R. T (1993). The regression-analog to survival analysis: A selected application to turnover research. Academy of Management Journal, 36, 1430-1464. 
Mossholder, K. W., Bedeian, A. G., Norris, D. R., Giles, W F, \& Feild, H. S. (1988). Job performance and turnover decisions: Two field studies. Journal of Management, 14, 403-413.

Nathan, B. R., \& Alexander; R. A. (1988). A comparison of criteria for test validation: A meta-analytic investigation. Personnel Psychology, 41, 517-535.

Nieva, V R, \& Gutek, B. A. (1980). Sex effects on evaluation. Academy of Management Review, 5, 267-276.

Olian, J. D., Schwab, D. P. \& Haberfeld, Y H. (1988). The impact of applicant gender compared to qualifications on hiring recommendations: A meta-analysis of experimental studies. Organizational Behavior and Human Decision Processes, 41, 180-195.

Park, H. Y, Ofori-Dankworth, J., \& Bishop, D. R. (1994). Organizational and environmental determinants of functional and dysfunctional turnover. Practical and research implications. Human Relations, 47, 353-366.

Peters. L. H., \& Sheridan, J. E. (1988). Turnover research methodology: A critique of traditional designs and a suggested survival alternative. In G. R. Ferris \& K. Rowland (Eds.), Research in personnel and human resources management (Vol. 6, pp. 231-262). Greenwich, CT JAI Press.

Porter, L. W., \& Lawler, E. E. (1968). Attitudes and performance. Homewood, IL: Irwin-Dorsey.

Rican i Costa, J. E. (1988). Assignments and promotion. Econometrica, 56, 449-466.

Rosenbaum, J. E. (1984). Career mobility in a corporate hierarchy. Orlando, FL: Academic Press.

SAS Institute. (1991). SAS Technical Report P-217 SAS/STAT software: The PHREG procedure (Version 6). Cary, NC: SAS Institute.

Schwab, D. P (1991). Contextual variables in employee performance-turnover relationships. Academy of Management Journal, 34, 966-975.

Sheridan, J. E. (1992). Organizational culture and employee retention. Academy of Management Journal, 35, 1036-1056.

Sheridan, J. E., Slocum, J. W, Buda, R., \& Thompson, R. (1990). Effects of corporate sponsorship and departmental power on career tournaments: A study of intra-organizational mobility. Academy of Management Journal, 33, 578-602.

Steers, R. M., \& Mowday. R. T (1981). Employee turnover and the post decision accommodation process. In B. M. Staw \& L. L. Cummings (Eds.), Research in organizational behavior (pp. 235-281). Greenwich, CT JAI Press.

Stumpf, S. A., \& Dawley, P K. (1981). Predicting voluntary and involuntary turnover using absenteeism and performance indices. Academy of Management Journal, 24, 148-163.

Teel, K. S. (1986). Are merit raises really based on merit? Personnel Journal, 65, 88-95. 
Thornton. G. C., \& Byham, W C. (1982). Assessment centers and managerial performance. New York: Academic Press.

Tosi, H. L., \& Einbender; S. W (1985). The effects of the type and amount of information in sex discrimination research: A meta-analysis. Academy of Management Journal, 28, 712723.

Viega, J. R (1985, August). To the beat of a different drummer: A comparison of managerial career paths. Paper presented at the Annual Meeting of the Academy of Management, San Diego, CA.

Waldman, M. (1990). Up-or-out contracts: A signaling perspective. Journal of Labor Economics, 8, 230-250.

Williams, C. R. (1990). Reward contingency and functional turnover. Dissertation Abstracts International, 53, 09A. (University microfilms no. 3140-00165).

Williams, C. R., \& Livingstone, L. P (1994). Another look at the relationship between performance and voluntary turnover. Academy of Management Journal, 37, 269-298.

Wright, T. A., \& Bonett, D. G. (1993). Role of employee coping and performance in voluntary employee withdrawal: A research refinement and elaboration. Journal of Management, 19, 147-161.

Zenger. T R. (1992). Why do employers only reward extreme performance? Examining the relationships among performance, pay, and turnover. Administrative Science Quarterly, $37,198-219$.

Received September 18, 1995 Revision received August 7, 1996

Accepted August 7, 1996 